\title{
EFEKTIVITAS STRETCHING ABDOMINAL DALAM PENGURANGAN NYERI AKIBAT DYSMENORRHEA PRIMER PADA REMAJA
}

\author{
Effectiveness of Abdomnal Stretching in Pain reduction Due To Primary Dysmenorrhea in \\ Adolescenst
}

Dwi Purwantini ${ }^{1}$, Elsa Davina Safanya ${ }^{2}$

${ }^{1}$ STIKES Katolik St. Vincentius a Paulo Surabaya

\section{Riwayat artikel \\ Diajukan: Agustus 2021 \\ Diterima: September 2021. \\ PenulisKorespondensi: \\ - Dwi Purwantini \\ - STIKES Katolik St. \\ Vincentius a Paulo \\ Surabaya \\ - dwiphysio@gmail.com}

\section{Kata Kunci:}

dysmenorrhea primer, stretching abdominal, VDS

\begin{abstract}
Abstrak
Stretching abdominal adalah penguluran yang berfokus pada bagian otot perut (otot rectus abdominis, obliqus internus, obliqus eksternus). Stretching sukses dalam mengobati/ mengurangi keluhan dysmenorrhea. Penelitian ini bertujuan untuk menganalisis pengaruh Stretching Abdominal terhadap penurunan tingkat dysmenorrhea primer. Jenis penelitian adalah quasi experimental dengan desain penelitian pre and post test control group design. Subyek penelitian adalah mahasiswi fisioterapi dengan dysmenorrhea primer sebanyak 40 mahasiswi yang dibagi dua kelompok. Kelompok kontrol tidak mendapatkan perlakuan dan kelompok eksperimen mendapatkan perlakukan intervensi Stretching Abdominal selama 10-15 menit. Subyek diukur kualitas nyeri dengan Verbal Descriptor Scale (VDS) sebelum dan sesudah stretching abdominal. Data penelitian menunjukkan pada kelompok kontrol nilai $\mathrm{p}=$ 0,52 yang berarti berarti Ho diterima sehingga hipotesis menyatakan bahwa tidak ada pengaruh terhadap penurunan skor VDS. Kelompok perlakuan nilai $\mathrm{p}=0,00$ Ho ditolak dan Ha diterima sehingga hiptesis menyatakan atretching abdominal memberikan pengaruh terhadap penurunan nilai VDS. Kesimpulan: stretching abdominal efektif terhadap penurunan tingkat dysmenorrhea primer
\end{abstract}

\section{Abstract}

Abdominal stretching is a stretching that focusing on the part of abdominal muscle (rectus abdominis, internus obliqus, external obliqus). Stretching is successful in reducing dysmenorrhea complaint. The aim of research to analyse the influence of abdominal stretching on reducing the level of primary dysmenorrhea. Methods: The studied design used was quasi experimental with pre and post control design. Subyek were 40 female physiotherapy student with primary dysmenorrhea devided into two groups. The experimental grup get abdominal stretching 10-15 minutes Results: The result of the researt showed that the control group had a $p$ value $=0.52$, which means that Ho is accepted, so the hypothesis states that there is no effect on the decrease in VDS scores. The treatment group $p=0.00$ Ho was rejected and Ha was accepted so the hypothesis stated that abdominal atretching had an effect on the impairment of VDS. Conclusion: abdominal stretching was effective in reducing level of primary dysmenorrhea 


\section{Pendahuluan}

Dysmenorrhea atau biasa disebut menstruasi adalah permasalahan ginekologi paling sering pada perempuan yang menimbulkan nyeri (Bobak et al., 2012), yang terjadi karena ketidakseimbangan hormone progresteron dalam darah (Prayitno, 2014). Dysmenorrhea tertinggi pada remaja perempuan dengan angka kejadian 20$90 \%$, dengan lebih dari 50\% Dysmenorrhea primer dan 10-15\% mengalami nyeri hebat sehingga mempengaruhi aktivitas dan kegiatan keseharian. Prevalensi Dysmenorrhea di Indonesia cukup tinggi yaitu 60-75\% yang terjadi pada wanita muda yang terdiri dari 54,89\% Dysmenorrhea primer dan 9,36\% Dysmenorrhea sekunder. Berdasarkan hasil survey pendahuluan pada mahasiswi di Fisioterapi ditemukan dari 55 mahasiswi yang berusia 19 tahun keatas yang mengalami dysmenorrhea, $76,4 \%$ (42 orang) mahasiswi mengalami dysmenorrhea dan $23,6 \%$ (13 orang) mahasiswi tidak mengalami dysmenorrhea, dan dari 76,4\% (42 orang) mahasiswi, $19 \%$ (8 orang) mahasiswi mengalami nyeri berat dan nyeri yang tak tertahankan, biasanya dikompres hangat, tiduran tetapi apabila nyeri tidak berkurang minum obat anti nyeri, 64\% (27 orang) mahasiswi mengalami nyeri cukup berat dan nyeri tidak begitu berat, hanya diberikan air putih tetapi kalau nyeri berlanjut baru mengonsumsi jamu tradisional kunyit asam atau diberikan kompres hangat dan $16,6 \%$ (7 orang) mahasiswi mengalami nyeri ringan dan tidak diberikan apa-apa sampai nyeri hilang. Mahasiswi yang mengalami dysmenorrhea saat ini belum ada yang melakukan stretching abdominal untuk mengurangi dysmenorrhea mereka rasakan. Prostaglandin F2 alfa (PGF2 $\alpha$ ) disekresi saat fase luteal dan aliran menstruasi berikutnya. Ischemia dan kram abdomen bawah yang bersifat siklik diakibatkan oleh karena pelepasan PGF2 $\alpha$ yang berlebihan sehingga meningkatkan ampliitudo dan frekuensi kontraksi uterus dan menyebabkan vasospasme arteriol uterus (Bobak et al., 2012). Respon sistemik terhadap PGF $2 \alpha$ meliputi nyeri punggung bawah dan keluhan system saraf pusat (pusing, sinkop, nyeri kepala). Prostaglandin yang dilepaskan secara berlebihan smpai sekarang tidak diketahu penyebabnya (Bobak et al., 2012).

Stretching/ penguluran adalah istilah umum yang digunakan untuk mendeskripsikan suatu latihan therapeutic yang bertujuan untuk meningkatkan ekstensibilitas jaringan lunak, sehingga meningkatkan fleksibilitas dan meningkatkan lingkup gerak dengan memanjangkan struktur yang memendek (Kisner \& Colby, 2012). Stretching abdominal adalah penguluran yang berfokus pada bagian otot perut (otot rectus abdominis, obliqus internus, obliqus eksternus). Stretching sukses dalam mengobati/ mengurangi keluhan dysmenorrhea (Hoeger \& Hoeger, 2015). Metode stretching aktif, artinya dilakukan sendiri tanpa bantuan dari kekuatan eksternal (Walker, 2011) dan tidak membutuhkan biaya (Johnson, 2012). Bentuk stretching aktif melibatkan hanya menggunakan kekuatan otot antagonis untuk menghasilkan peregangan dalam kelompok otot yang ditargetkan (agonis) (Walker, 2011). Stretching abdominal ini terdiri dari 5 latihan yaitu On elbow stomach strecth, Rising stomach stretch, rotation stomach stretch, Standing leanback stomach stretch, standing lean-back side stomach stretch (Walker, 2011). Stretching abdominal dilakukan "within pain free range" atau penguluran dilakukan dalam batas tanpa adanya nyeri, untuk keamanan (Johnson, 2012).

Penelitian ini dilakukan untuk menganalisis pengaruh tingkat dysmenorrhea primer sebelum dan sesudah dilakukan stretching abdominal pada mahasiswi Fisioterapi STIKES Katolik St. Vincentius a Paulo Surabaya. 


\section{Metodologi}

Desain penelitia ini menggunakan quasi ekperiment dengan pre and post test controll grup design. Dua kelompok digunakan pada penelitian ini yaitu kelompok kontrol dan kelompok perlakuan/eksperiment, dimana kelompok kontrol tidak mendapatkan perlakukan dan kelompok eksperiment diberikan perlakuan stretching abdominal.

Penelitian dilakukan selama bulan JuniJuli 2020 tempat di rumah masingmasing dengan pemantauan selama melakukan stretching. Sasaran dari penelitian adalah mahasiswi fisioterapi berusia di atas 18 tahun berjumlah 40 mahasiswi Fisioterapi yang memenuhi kriteria inklusi yaitu mengalami nyeri haid ringan sampai berat dan tidak mengkonsumsi obat analgesic yang lain. Teknik pengambilan data dengan total sampling.

Tujuan penelitian, manfaat dan prosedur pelaksanaan dijelaskan oleh peneliti pada responden. Peneliti memberikan surat persetujuan (informed consent) untuk ditanda tangani, kemudian peneliti membagi menjadi dua kelompok, kelompok kontrol tidak mendapatkan perlakukan, hanya didiamkan dan diukur nyeri sebelum dan sesudah serta kelompok eksperimen mendapatkan perlakukan dengan stretching abdominal.

Pengumpulan data dilakukan observasi terlibat, dimana observasi tersebut dilakukan dan diukur oleh responden sendiri, yaitu sebelum dilakukan intervensi. Kualitas nyeri diukur dengan Verbal Descriptor scale (VDS) (Łęcka, 2013). Sebelum memberikan stretching abdominal responden mengisi skala nyeri VDS dalam lembar observasi yang telah dibagi oleh peneliti untuk diisi responden saat responden mengalami nyeri haid. Kemudian intervensi dilakukan selama 10-15 menit. Setelah intervensi dilakukan, peneliti melakukan pengukuran dengan skala dysmenorrhea yang diisi oleh responden sendiri pada lembar observasi menggunakan skala nyeri VDS. Panduan stretching abdominal dibuat booklet disertai prosedur melakukan penelitian yang dibawa subyek penelitian. Selanjutnya subjek melakukan stretching abdominal secara mandiri berurutan sesuai tahaptahap yang ada di booklet.

Analisis data univariate berupa umur, tinggi badan (TB), berat badan (BB), body mass index, dan usia menarche usia merupakan data numerik dan disajikan dalam dalam mean dan standar deviasi. Analisis bivariate penelitian ini menggunakan uji normalitas data menggunakan Saphiro-wilk dan data menunjukkan data tidak berdistribusi normal. Selanjutnya dilakukan uji homogenitas didapatkan data sebelum perlakuan dan sesudah perlakuan homogeny/ tidak ada perbedaan varian. Selanjutnya karena data tidak berdistribusi normal uji hipotesiis dengan menggunakan Wilcoxon untuk melihat adanya perbedaan pengaruh yang tidak mendapatkan perlakukan dan yang mendapatkan perlakukan stretching abdominal. Penarikan kesimpulan dari tiap uji dengan nilai $\alpha=0,05$. H1 diterima bila nilai $\mathrm{p}<\alpha=0,05$.

\section{Hasil dan Pembahasan}

Data deskriptif yang diperoleh terdiri dari umur, tinggi badan (TB), berat badan (BB), body mass index, dan usia menarche. Hasil data deskriptif berupa rerata dan simpang baku ditunjukkan pada tabel 1 .

Berdasarkan data di atas diketahui rerata dan simpang baku usia subyek penelitian adalah 20,43 $\pm 4,19$ dengan 18 tahun usia minimal dan 24 tahun usia maximal. Nilai rerata dan simpang baku berat badan subyek penelitian adalah $55,78 \pm 10,23$ dengan berat badan minimal $38 \mathrm{~kg}$ dan berat badan maksimal $78 \mathrm{~kg}$. Nilai rerata dan simpang baku tinggi badan subyek penelitian adalah $156,48 \pm 6,48$ dengan tinggi badan minimal $141 \mathrm{~cm}$ dan tinggi badan 
maksimal $168 \mathrm{~cm}$. Nilai rerata dan simpang baku indeks massa tubuh subyek penelitian adalah $22,76 \pm 4,10$ dengan indeks massa tubuh minimal 16,1 dan indeks massa tubuh maksimal 34,7. Nilai rerata dan simpang baku usia menarche subyek penelitian adalah $12,70 \pm 1,60$ dengan usia menarche minimal 9 tahun dan usia menarche maksimal 19 tahun.

Uji Shapiro Wilk digunakan untuk uji normalitas data didapatkan nilai $\mathrm{p}$ masing-masing kelompok baik sebelum intervensi dengan skor Verbal Descriptor Scale (VDS) seluruh nilai $\mathrm{p}>0,05$ yang artinya data berdistribusi normal, tetapi masing-masing kelompok sesudah intervensi menunjukkan nilai $\mathrm{p}<0,05$ yang artinya data tidak berditribusi normal. Dengan demikian seluruh data pengukuran variable akan dianalisis lebih lanjut dengan menggunakan uji metode non parametric

Uji homogenitas varians skor Verbal Descriptor Scale (VDS) sebelum perlakuan didapatkan nilai $\mathrm{p}=0,64$ ( $p>0,05)$. Uji homogenitas varian skor VDS setelah mendapatkan perlakuan kelompok kontrol dan kelompok perlakuan dipeoleh $\mathrm{p}=0,35 \quad(\mathrm{p}>0,05)$. Nilai $p>0,05$ diperoleh 2 kelompok yang berarti kedua kelompok perlakuan tidak ada perbedaan varian/ data homogen.

Uji normalitas didapatkan bahwa data berdistribusi tidak normal, maka kelompok kontrol dan kelompok perlakuan dilakukan uji hipotesa dengan menggunakan analisis Wilcoxon. Pada kelompok kontrol hasil uji statistic Wilcoxon adalah $\mathrm{p}=0,52$ ( $\mathrm{p}>0,05)$ yang berarti Ho diterima sehingga hipotesis menyatakan bahwa tidak ada pengaruh terhadap penurunan skor VDS. Sedangkan pada kelompok perlakuan mendapatkan stretching abdominal hasil uji statistic Wilcoxon adalah $\mathrm{p}=0,00$ $(\mathrm{p}<0,05)$ yang berarti Ho ditolak dan $\mathrm{Ha}$ diterima sehingga hiptesis menyatakan atretching abdominal memberikan pengaruh terhadap penurunan nilai VDS pada mahasiswi Fisio STIKES Katolik St. Vincentius a Paulo Surabaya.

Tabel 1 Nilai rerata dan simpang baku usia, TB, BB, IMT dan usia menarche

\begin{tabular}{cccc}
\hline No & Variabel & $\mathrm{N}$ & Rerata \pm SD \\
\hline 1. & Umur (tahun) & 40 & $20,43 \pm 4,19$ \\
2. & $\begin{array}{c}\text { Berat badan } \\
(\mathrm{kg})\end{array}$ & 40 & $55,78 \pm 10,23$ \\
& $\begin{array}{c}\text { Tinggi Badan } \\
(\mathrm{cm})\end{array}$ & 40 & $156,48 \pm 6,48$ \\
3. & BMI & 40 & $22,76 \pm 4,10$ \\
4. & $\begin{array}{c}\text { Usia } \\
\text { menarche }\end{array}$ & 40 & $12,70 \pm 1,60$ \\
\hline
\end{tabular}

Tabel 2. Uji Normalitas

\begin{tabular}{|c|c|c|c|}
\hline \multirow{2}{*}{ No } & \multirow{2}{*}{ Variabel } & \multicolumn{2}{|c|}{ Nilai p } \\
\hline & & Pre & Post \\
\hline 1. & $\begin{array}{l}\text { Nilai VDS Kelompok } \\
\text { Kontrol }\end{array}$ & 0,33 & 0,00 \\
\hline 2. & $\begin{array}{l}\text { Nilai VDS Kelompok } \\
\text { perlakuan (Stretching } \\
\text { Abdominal) }\end{array}$ & 0,17 & 0,03 \\
\hline
\end{tabular}

Tabel 3. Uji Homogenitas

\begin{tabular}{clc}
\hline No & \multicolumn{1}{c}{ Variabel } & Nilai $\mathrm{p}$ \\
\hline 1. & $\begin{array}{l}\text { Nilai VDS sebelum } \\
\text { intervensi }\end{array}$ & 0,64 \\
2. & $\begin{array}{l}\text { NIlai VDS sesudah } \\
\text { intervensi }\end{array}$ & 0,35 \\
\hline
\end{tabular}

Tabel 4. Hasil Uji Wilcoxon

\begin{tabular}{lllccc}
\hline \multirow{2}{*}{ No } & Variabel & $\mathrm{N}$ & \multicolumn{2}{c}{ Rerata \pm SD } & $p$ \\
\cline { 4 - 5 } & & Nilai VDS & Pre & Post & \\
1. & $\begin{array}{l}\text { Kelompok } \\
\text { Kntrol }\end{array}$ & 18 & $3,50 \pm 1,43$ & $3,11 \pm 1,37$ & 0,52 \\
& Nilai VDS & & & & \\
Kelompok & & & & \\
2. & $\begin{array}{l}\text { Perlakuan } \\
\text { (Stretching }\end{array}$ & 22 & $3,68 \pm 1,36$ & $1,77 \pm 1,23$ & 0,00 \\
& Abdominal & & & \\
\hline
\end{tabular}

Dysmenorrhea merupakan kondisi nyeri sangat sering terjadi pada wanita 
terutama remaja, yang merupakan permasalahan ginekologis. Tujuan dari dilakukannya penelitian ini untuk menganalisis apakah stretching abdominal berpengaruh dalam pengurangan nyeri akibat dysmenorrhea primer dan juga melihat apakah stretching abdominal ini lebih efektif dibandingkan dengan tidak melakukan apapun. Pada kelompok kontrol terjadi penurunan skor VDS dari 3,50 $\pm 1,43$

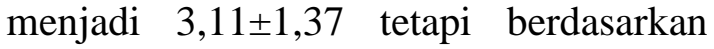
hasil hasil uji statistic Wilcoxon menunjukkan tidak terdapat perbedaan dengan nilai $p>0,05 \quad(p=0,52)$. HAsil tersebut menunjukkan tanpa mendapatkan perlakuan apapun dalam penelitian ini istirahat 10-15 menit dapat terjadi penurunan skor VDS tetapi tidak signifikan. Pada kelompok perlakuan menunjukkan adanya perbedaan yang bermakna terhadap penurunan skor VDS sebelum dan sesudah perlakuan dengan stretching abdominal $(\mathrm{p}=0,00)$. Nilai rerata skor VDS dari 3,68 $\pm 1,36$ menjadi $1,77 \pm 1,23$. Hal ini menunjukkan stretching abdominal yang dilakukan berpengaruh terhadap penurunan skor VDS. Hal ini sejalan dengan beberapa penelitian bahwa latihan stretching efektif dalam mengurangi intensitas nyeri, durasi nyeri dan dapat digunakan sebagai penghilang nyeri pada remaja perempuan dengan dysmenorrhea primer(Shahr-jerdy et al., 2013). Latihan aktif stretching mudah dan merupakan manajemen tanpa obat yang dapat mengurangi keluhan pada dysmenorrhea primer (S Saleh \& E Mowafy, 2016). Sedangkan penelitian yang dilakukan (Onur et al., 2012), program latihan yang terdiri dari stretching, latihan aerobic dan latihan relaksasi dapat meningkat kualitas hidup perempuan dengan dysmenorrhea primer

Hasil uji statistic Wilcoxon adalah $\mathrm{p}=0,52 \quad(\mathrm{p}>0,05)$ yang berarti Ho diterima sehingga hipotesis menyatakan bahwa tidak ada pengaruh terhadap penurunan skor VDS. Sedangkan pada kelompok perlakuan mendapatkan stretching abdominal hasil uji statistic Wilcoxon adalah $\mathrm{p}=0,00(\mathrm{p}<0,05)$ yang berarti Ho ditolak dan $\mathrm{Ha}$ diterima sehingga hipotesis menyatakan atretching abdominal memberikan pengaruh terhadap penurunan skor VDS. Nyeri menstruasi disebabkan oleh prostraglandin yang disekresi mengalami peningkatan pada darah menstruasi sehingga intensitas kontraksi uterus yang normal juga meningkat. Perempuan dengan dysmenorrhea primer mengalami pembentukan berlebihan $\mathrm{PGF}_{2 \alpha}$ akibat kontraksi miometrium yang berlebihan yang diakibatkan oleh vasopressin (Corwin, 2010). Stretching abdominal dapat membantu meningkatkan proses pertukaran oksigen yang disebut dengan oksigenasi dan karbohidrat di dalam sel serta merangsang aliran drainase sistem getah bening, sehingga fleksibilitas otot akan meningkat dan membuat otot-otot kembali pada panjang alamiah dan dapat memelihara fungsinya dengan baik serta meningkatkan elastisitas atau fleksibilitas jaringan tubuh serta mengurangi kram pada otot (Ningsih \& Rahmah, 2013). Latihan stretching secara rutin bermanfaat untuk membantu mempertahankan mobilitas sendi tetap baik, meningkatkan ketahanan terhadap cedera otot dan rasa nyeri, mencegah nyeri punggung bawah dan problem spinal lainnya, meningkatkan penampilan personal dan self image, serta sukses dalam mengobati/ mengurangi keluhan dysmenorrhea (Hoeger \& Hoeger, 2015). Hasil penelitian ini menunjukkan bahwa stretching abdominal efektif dalam penurunan tingkat dysmenorrhea primer.

\section{Simpulan}

Stretching abdominal efektif dalam penurunan tingkat dysmenorrhea primer, sehingga dapat digunakan sebagai alternatif dalam mengurangi rasa nyeri karena menstruasi

Penelitian selanjutnya selain dilihat dari kualitas nyeri juga bisa ditambahkan kualitas hidup. Teknik stretching 
abdominal ini dapat dilakukan secara rutin supaya keluhan yang dirasakan akibat dysmenorrhea primer berkurang dan waktu keluhan pun menjadi berkurang.

\section{Daftar Pustaka}

Bobak, I. M., Lowdermilk, D. L., Jensen, M. D., \& Perry, S. E. (2012). Buku Ajar Keperawatan Maternitas (R. Komalasari (ed.); Edisi 4). EGC.

Corwin, E. J. (2010). Buku Saku Patofisiologi. EGC.

Hoeger, W. ., \& Hoeger, S. A. (2015). Fitness and Wellness (Eleventh e). Cengage Learning.

Johnson, J. (2012). Therapeutic Stretching, Hand-On Guides for Therapists. Human Kinetics.

Kisner, C., \& Colby, L. A. (2012). Therapeutic Exercise Foundation and Technique.

Łęcka, M. (2013). Pain assessment and the role of verbal descriptors of pain in the English language Rola słownych określeń odczuwania bólu $w$ ocenie bólu $w$ języku angielskim. 268-275.

Ningsih, R., \& Rahmah, H. (2013). Efektivitas paket pereda nyeri pada remaja. Jurnal Keperwatan Indonesia, 16(2), 67-76.

Onur, O., Gumus, I., Derbent, A., Kaygusuz, I., Simavli, S., Urun, E., Yildirim, M., Gok, K., \& Cakirbay, H. (2012). Impact of home-based exercise on quality of life of women with primary dysmenorrhoea. South African Journal of Obstetrics and Gynaecology, 18(1), 15-18. https://doi.org/10.7196/sajog.391

Prayitno, S. (2014). Buku lengkap Kesehatan Reproduksi Wanita (H. Susanto (ed.)). Saufa.

S Saleh, H., \& E Mowafy, H. (2016). Stretching or Core Strengthening
Exercises for Managing Primary Dysmenorrhea. Journal of Womens Health Care, 05(01), 1-6. https://doi.org/10.4172/21670420.1000295

Shahr-jerdy, S., Hosseini, R. S., \& Gh, M. E. (2013). Effects of stretching exercises on primary dysmenorrhea in adolescent girls. Biomedical Human Kinetics, 4, 127-132. https://doi.org/10.2478/v10101-0120024-y

Walker, B. (2011). Ultimate Guide to Stretching and Flexibility. Third Edition (Third Edit). Injury fix and Stretching Institute Injury fix and Stretching Institute. 